\title{
Effect of Bacillus subtilis natto on Growth Performance in Muscovy Ducks
}

\section{-Author(s)}

Sheng-Qiu Tal

Xiao-Ying $D$ ab1

Chun-Mei J a

Jing-Jing $P b$

Shan-Shan L

Jin-Ding $C$ b*

These authors contributed equally to this work

a. Department of Agricultural Science, Shaoguan University, Shaoguan 512005, China;

b. College of Veterinary Medicine, South China Agricultural University, Guangzhou 510642, China

\section{ABSTRACT}

The aim of the present study was to determine whether dietary Bacillus subtilis natto could affect growth performance of Muscovy ducks. A total of 120 hundred Muscovy ducks at the age of 1 day were randomly assigned to four groups (30 Muscovy ducks/group), and fed with diets supplemented with $0 \%$ (control group), $0.1 \%, 0.2 \%$, and $0.4 \%$ Bacillus subtilis natto, respectively during the 6 -week feeding period. Weight gain, feed intake and feed conversion efficiency of Muscovy ducks were significantly improved by the dietary addition of Bacillus subtilis natto, and the results were more significant in $0.4 \%$ dietary Bacillus subtilis natto treatment group; Also, Bacillus subtilis natto reduced Escherichia coli and Salmonella colonies, and increased lactobacilli population in the ileum and the cecum. Biochemical parameters, including total protein, GOT (glutamic oxaloacetic transaminase), GPT (glutamic pyruvic transaminase), AKP (alkaline phosphatase), triiodothyronine $\left(T_{3}\right)$ and tetraiodothyronine $\left(T_{4}\right)$ contents $(p<0.05)$ in the serum of Muscovy ducks were significantly improved $(p<0.01)$, while urea nitrogen, glucose, triglyceride, total cholesterol concentrations decreased when Bacillus subtilis natto was added to the diets $(p<0.05)$, and improved duodenum and immune functions. However, the results above were not significantly different between birds fed $0.1 \%$ Bacillus subtilis natto supplemented diets and the control group ( $p>0.05)$. The results of the present study indicate that diets with $0.4 \%$ Bacillus subtilis natto improved the growth performance of Muscovy ducks by increasing the absorption of protein, simulating hormone secretion, suppressing harmful microflora, and improving the duodenal structure and immune functions of Muscovy ducks. It is suggested that Bacillus subtilis natto is a potential candidate to be used use as a probiotic to improve the growth performance of Muscovy ducks.

\section{INTRODUCTION}

Probiotics have been used as feed additives to replace antibiotics, as these may induce resistance and leave residues in animal products (Steiner, 2006). The main probiotic strains are Bacillus, Lactobacillus, Streptococcus, Saccharomyces and Aspergillus (Tannock, 2001). Bacillus subtilis may secrete protease, amylase, and lipase, which are important to improve the growth performance and to control diseases in animals (Santoso et al., 2001). Therefore, development and application of Bacillus subtilis as a feed additive may be useful.

Bacillus subtilis natto, a strain of Bacillus subtilis, is the basis for the production of the traditional Japanese food "natto", made from soybeans. Soybean natto, fermented by Bacillus subtilis natto, may potentially become a functional and health food because of its high antioxidant activity ( $\mathrm{Hu}$ et al., 2010). Furthermore, previous findings demonstrated that many enzymes purified from Bacillus 
subtilis natto, such as methyltransferase, gammaglutamyltranspeptidase, alanine dehydrogenase, leucine dehydrogenase, and serine proteinase, are functional (Shih et al., 2005). The protein derived from Bacillus subtilis natto had both fibrinolytic and antithrombotic effects similar to heparin (Omura et al., 2005), enhancing endogenous thrombolysis in a dose-dependent manner (Yamashita et al., 2003). A lipopeptide biosurfactant purified from Bacillus subtilis natto was able to inhibit the proliferation of human breast-cancer cells (Cao et al., 2009) and human leukemia cells (Wang et al., 2007), indicating the antitumour activity of Bacillus subtilis natto. Also, it was shown that Bacillus subtilis natto contains nattokinase, which displays strong fibrinolytic activity and activates other fibrinolytic enzymes, such as pro-urokinase and tissue plasminogen activator (Yanagisawa et al., 2010).

There are few studies reported in literature on the effects of Bacillus subtilis natto supplementation in the diets of fish, livestock and poultry (Samanya and Yamauchi, 2002; Chen et al., 2009; Liu et al., 2009; Sun et al., 2010) because of its many diverse functions. To date, no study was reported on the supplementation Bacillus subtilis natto in the diets of Muscovy ducks. The present study evaluated the effects of Bacillus subtilis natto on the growth performance of Muscovy ducks.

\section{MATERIALS AND METHODS}

\section{Experimental Design and Treatments}

A total of 120 Muscovy ducks (Cairina moschata) with almost the same body weight (45-48g) were obtained from a commercial breeding company (Donglian, Shaoguan, China), and randomly distributed into four groups, with 30 Muscovy ducks per group. Birds were daily fed a commercial diet and water ad libitum during the 6-week study. Ingredients and nutritional composition of the basal diet, formulated were according with INRA requirements (1984), are shown in Table 1. All data were measured, except for metabolic energy (ME).

Diets were supplemented with four levels of Bacillus subtilis natto: diets with $0 \%$ of Bacillus subtilis natto was set as control group, and those with $0.1 \%, 0.2 \%$, and $0.4 \%$ Bacillus subtilis natto were set as treatment groups. Diets were supplied daily, and clean drinking water was supplied ad libitum during the 6-week feeding period. Birds were exposed to infrared lamp before 3 weeks and then to incandescent light a period of 12-hour (12L:12D) each day. Temperature and ventilation were controlled. The temperature was set at $20-27^{\circ} \mathrm{C}$ throughout the experiment.
Table 1 - Ingredients and nutritional compositios of the experimental basal diets \%

\begin{tabular}{lcc}
\hline \multirow{2}{*}{ Basal diets } & \multicolumn{2}{c}{ Bird age } \\
\cline { 2 - 3 } & $1-3$ weeks & $3-6$ weeks \\
\hline Ingredients (\%) & & \\
\hline Ground yellow corn & 60.00 & 24.70 \\
\hline Rough rice & --- & 40.00 \\
\hline Wheat bran & 7.00 & 10.00 \\
\hline Soybean meal & 21.25 & 13.55 \\
\hline Fish meal & 5.00 & 3.50 \\
\hline Yeast Powder & 4.00 & 3.00 \\
\hline Soybean oil & --- & 2.00 \\
\hline Calcium monohydrogen & 1.00 & 1.50 \\
phosphate & & \\
\hline Salt & 0.25 & 0.25 \\
\hline Mineral and vitamin premix & 1.50 & 1.50 \\
\hline Analyzed chemical composition & & \\
\hline Crude protein (\%) & 19.20 & 16.00 \\
\hline Calcium (\%) & 1.16 & 1.25 \\
\hline Available phosphorus (\%) & 0.55 & 0.65 \\
\hline Lysine (\%) & 1.00 & 0.65 \\
\hline Methionine (\%) & 0.50 & 0.33 \\
\hline Methionine + Cystine (\%) & 0.85 & 0.63 \\
\hline ME (MJ/kg) & 11.50 & 9.80 \\
\hline
\end{tabular}

'Supplied per kilogram of premix: vitamin A, 1,200,000 IU; vitamin E, 2000 IU; vitamin $\mathrm{D}_{3^{\prime}}, 250,000 \mathrm{IU}$; vitamin $\mathrm{K}_{3^{\prime}} 200 \mathrm{mg}$; vitamin $\mathrm{B}_{1}, 100 \mathrm{mg}$; vitamin $\mathrm{B}_{2^{\prime}} 800 \mathrm{mg}$; vitamin $B_{6}$, 200mg; vitamin $B_{12}, 1.0 \mathrm{mg}$; folic acid, $200 \mathrm{mg}$; biotin, $5 \mathrm{mg}$; niacin, 7,500mg; pantothenic acid, 1000 mg; Mn, 10.0 g; Zn, 10.0 g; Fe, 7.5 g; Cu, 0.5 g; I, 200 mg; Cr, $10.0 \mathrm{mg}$; and Se, $15 \mathrm{mg}$.

${ }^{2}$ The data is calculated

\section{Performance Calculation and Sample Collection}

Ducks were weighed with one day of age and at the end of the experiment. Daily feed intake was recorded daily. Moreover, feed conversion ratio (feed intake/ weight gain) was calculated for during the 6-week feeding period.

Ten ducks per group were selected and weighed on day 42 of the feeding trial. Blood samples $(8.0 \mathrm{ml})$ from each individual were collected from the heart with sterilized syringes and needles. Then the ducks were killed by exsanguination and were dissected. The thymus, spleen and bursa of Fabricius were collected and weighed. The immune organ index (in $\mathrm{g} / \mathrm{kg}$ ) was calculated by dividing immune organ weight by the body weight of the ducks. Furthermore, segments of approximately $2 \mathrm{~cm}$ were collected from duodenum (posterior to gizzard) for intestinal morphometry. Also, $2 \mathrm{~cm}$ of the ileum and the cecum with contents were stored in sterile plastic bags to measure intestinal tract microflora population. 


\section{Analysis of serum biochemical parameters}

The collected blood samples were centrifuged (4000 rpm) for $6 \mathrm{~min}$ and then the obtained serum samples were stored at $-70^{\circ} \mathrm{C}$ until further analysis. The concentrations of total protein, glucose, triglyceride, total cholesterol, urea nitrogen, GOT, GPT and AKP were measured using enzyme reagent methods. The assay kits were provided by Ningbo Cicheng Biochemistry Reagent Factory.

The levels of $T_{3}$ and $T_{4}$ in serum were analyzed using the method of radio-immunity (RI). The assay kits of hormones were provided by Beijing North Institute of Biological Technology (20a Panjiamiao, Fengtai District, Beijing, China).

\section{Intestinal Morphometry}

According to the method described by Becak and Paulete (1976), the duodenum segments collected on the last day of the feeding period were placed on polystyrene sheets, longitudinally opened, washed in saline solution, fixed in Bouin's solution for 24h, and processed until paraffin embedding. Each fragment was submitted to semi-serial cuts ( $5 \mathrm{~mm}$ thick) and stained using the hematoxylin-eosin method.

In the morphometric study of duodenum, images were captured using a light microscope and a system that analyzes computerized images. The height and width of 30 villi, the depth of 30 crypts, and the thickness of 30 muscular layers were measured in all segments per replicate. The villus perimeter was based on the villus circumference and the distance between neighboring villi. Crypt depth was the shortest vertical distance from the villus contact point to the mucous membrane. The muscle layer was the shortest vertical distance from the point between the epimysium and annular muscle to the mucous membrane.

\section{Analysis of intestinal Tract Microflora Population}

Ileum and cecum contents were diluted 10-fold with buffered peptone water, vortexed for $2 \mathrm{~min}$ and the supernatant was preserved at $-70^{\circ} \mathrm{C}$. One hundred microliters of supernatant was smeared onto MacConkey agar and incubated at $37^{\circ} \mathrm{C}$ for $24 \mathrm{~h}$ to enumerate Escherichia coli colonies, on Rogosa agar at $37^{\circ} \mathrm{C}$ for $48 \mathrm{~h}$ to measure lactobacilli population, or on $\mathrm{SS}$ agar at $37^{\circ} \mathrm{C}$ for $24 \mathrm{~h}$ to count Salmonella colonies, respectively, in triplicate.

\section{STATISTICAL ANALYSIS}

The experiment was conducted according to a completely randomized design. The SAS (Statistical Analysis System, SAS Institute Inc, Cary, NC, USA, Version 9.1.3) software package was used for all statistical analysis. Duncan's multiple range test $(p<0.05)$ was used to test the significance of the difference among means. All data were expressed as means \pm SD. Differences were considered significant at the level of $p<0.05$.

\section{RESULTS}

\section{Effects of Bacillus subtilis natto on growth performance of Muscovy ducks}

The effect of Bacillus subtilis natto on the growth performance in Muscovy ducks fed with the diets supplemented with $0 \%, 0.1 \%, 0.2 \%$, and $0.4 \%$ Bacillus subtilis natto is shown in Table 2. After a feeding period of 6 weeks, weight gain $(p<0.05)$, feed intake $(p<0.05)$ and feed conversion ratio $(p<0.01)$ of Muscovy ducks significantly improved when $0.2 \%$ and $0.4 \%$ Bacillus subtilis natto were added to the diets, and the results were more evident in the $0.4 \%$ dietary Bacillus subtilis natto treatment; however, weight gain, feed intake and feed conversion ratio were not significantly different between Muscovy ducks fed with $0.1 \%$ Bacillus subtilis natto supplemented diets compared with the control group ( $p>0.05)$.

Table 2 - Effect of the dietary addition of Bacillus subtilis natto on the growth performance of Muscovy ducks ${ }^{1}$

\begin{tabular}{|c|c|c|c|c|c|}
\hline \multirow[b]{2}{*}{ Items } & \multicolumn{4}{|c|}{ Levels of Bacillus subtilis natto (\%) } & \multirow[b]{2}{*}{ SEM } \\
\hline & $\begin{array}{c}0 \\
\text { (control) }\end{array}$ & 0.1 & 0.2 & 0.4 & \\
\hline $\begin{array}{l}\text { Weight gain } \\
\text { (g/bird/d) }\end{array}$ & $32.38^{a}$ & $32.47^{\mathrm{a}}$ & $33.47^{b}$ & $34.49^{c}$ & 0.19 \\
\hline $\begin{array}{l}\text { Feed intake } \\
(\mathrm{g} / \mathrm{bird} / \mathrm{d})\end{array}$ & $88.11^{\mathrm{a}}$ & $87.67^{a}$ & $88.22^{\mathrm{ab}}$ & $89.08^{b}$ & 0.17 \\
\hline $\begin{array}{l}\text { Feed conversion }{ }^{2} \\
(\mathrm{~g} / \mathrm{g})\end{array}$ & $2.72^{\mathrm{a}}$ & $2.70^{a}$ & $2.64^{b}$ & $2.58^{c}$ & 0.07 \\
\hline
\end{tabular}

$a, b, c$ Different letters for the same line denote significant differences $(p<0.05)$.

1 Values represent the means \pm SEM of 10 Muscovy ducks per group.

${ }^{2}$ Feed conversion = feed intake: weight gain $(\mathrm{g}: \mathrm{g})$.

\section{Effects of Bacillus subtilis natto on serum biochemical parameters of Muscovy ducks}

The levels of total protein, glucose, triglyceride, total cholesterol, urea nitrogen, GOT, GPT, AKP, $T_{3}$ and $T_{4}$ in the different treatments were measured and are shown in Table 3. The results indicated that 
Table 3 - Effect of dietary Bacillus subtilis natto levels on biochemical parameters of Muscovy ducks ${ }^{1}$

\begin{tabular}{|c|c|c|c|c|c|}
\hline \multirow{2}{*}{ Items } & \multicolumn{4}{|c|}{ Levels of Bacillus subtilis natto, \% } & \multirow{2}{*}{ SEM } \\
\hline & 0 (control) & 0.1 & 0.2 & 0.4 & \\
\hline Total protein $(\mathrm{g} / \mathrm{l})$ & $38.79^{a}$ & $38.62^{\mathrm{a}}$ & $42.53^{b}$ & $46.43^{c}$ & 0.62 \\
\hline Glucose (mg/ml) & $0.10^{\mathrm{a}}$ & $0.094^{\mathrm{ab}}$ & $0.092^{b}$ & $0.088^{b}$ & 0.01 \\
\hline Triglyceride (mg/ml) & $16.35^{a}$ & $16.15^{\mathrm{ab}}$ & $15.84^{b}$ & $14.35^{c}$ & 0.14 \\
\hline Total cholesterol (mg/ml) & $2.07^{\mathrm{a}}$ & $2.02^{\mathrm{a}}$ & $1.85^{b}$ & $1.76^{b}$ & 0.03 \\
\hline Urea nitrogen $(\mathrm{mg} / \mathrm{ml})$ & $0.107^{\mathrm{a}}$ & $0.099^{a}$ & $0.087^{b}$ & $0.077^{b}$ & 0.003 \\
\hline GOT(U/l) & $56.74^{\mathrm{a}}$ & $59.19^{b}$ & $60.11^{b}$ & $64.52^{c}$ & 0.48 \\
\hline GPT(U/I) & $65.49^{a}$ & $68.42^{b}$ & $72.43^{c}$ & $76.65^{d}$ & 0.70 \\
\hline $\mathrm{AKP}(\mathrm{U} / \mathrm{l})$ & $134.58^{\mathrm{a}}$ & $136.84^{b}$ & $143.83^{c}$ & $158.55^{d}$ & 1.50 \\
\hline $\mathrm{T}_{3}(\mathrm{ng} / \mathrm{ml})$ & $5.28^{\mathrm{a}}$ & $5.71^{\mathrm{b}}$ & $6.64^{c}$ & $7.29^{d}$ & 0.13 \\
\hline $\mathrm{T}_{4}(\mathrm{ng} / \mathrm{ml})$ & $15.05^{\mathrm{a}}$ & $16.11^{b}$ & $17.36^{c}$ & $18.63^{d}$ & 0.22 \\
\hline
\end{tabular}

$a, b, c, d$ Different letters in the same row indicate significant differences $(p<0.05)$.

1 Values represent the means \pm SEM of 10 Muscovy ducks per group.

treatment with $0.1 \%$ dietary Bacillus subtilis natto had little effect on total protein, glucose, triglyceride, total cholesterol and urea nitrogen levels ( $p>0.05)$, but increased the secretion of GOT, GPT, AKP, $T_{3}$ and $T_{4}$ $(p<0.05)$. Total protein, GOT, GPT, AKP, $T_{3}$ and $T_{4}$ blood levels significantly increased $(p<0.05)$, and glucose, triglyceride, total cholesterol and urea nitrogen levels significantly decreased $(p<0.01)$ when the birds were fed with $0.2 \%$ and $0.4 \%$ Bacillus subtilis natto in diets.

\section{Effects of Bacillus subtilis natto on microflora population in ileum and cecum of Muscovy ducks}

As shown in Table 4, Escherichia coli, Salmonella, and lactobacilli levels changed when Bacillus subtilis natto was added to the diets. Compared with the control treatment, $0.1 \%$ Bacillus subtilis natto reduced Escherichia coli and Salmonella counts, and increased lactobacilli counts, but this effect was not significant ( $p>0.05) ; 0.2 \%$ Bacillus subtilis natto promoted better effects $(p<0.05)$. Furthermore, the effect of $0.4 \%$
Bacillus subtilis natto on the microflora population was more significant $(p<0.01)$.

\section{Effects of Bacillus subtilis natto on development of duodenum of Muscovy ducks}

The intestinal morphology of duodenum in different treatments is shown in Table 5. Compared with the control group, birds fed $0.1 \%$ Bacillus subtilis natto had a higher villus height and villus width in the duodenum $(p<0.05)$, but there was no statistically significant difference in crypt depth and muscular layer thickness ( $p>0.05$ ). The dietary levels of $0.2 \%$ and $0.4 \%$ Bacillus subtilis natto clearly improved the growth of duodenum and promoted the longest villus height and largest absorptive surface area. Villus width, villus height, crypt depth, and muscular layer thickness results demonstrated that $0.1 \%$ and $0.2 \%$ Bacillus subtilis natto were able to promote the development of duodenum, but failed to match the performance of $0.4 \%$ Bacillus subtilis natto $(p<0.01)$.

Table 4 - Effect of different levels Bacillus subtilis natto on microflora in Muscovy ducks ${ }^{1}$

\begin{tabular}{|c|c|c|c|c|c|c|}
\hline & \multirow{2}{*}{ Items } & \multicolumn{4}{|c|}{ Levels of Bacillus subtilis natto, \% } & \multirow{2}{*}{ SEM } \\
\hline & & 0 (control) & 0.1 & 0.2 & 0.4 & \\
\hline \multirow{3}{*}{ Ileum } & Escherichia coli & $6.88^{\mathrm{a}}$ & $6.66^{\mathrm{ab}}$ & $6.45^{b}$ & $5.98^{c}$ & 0.07 \\
\hline & Salmonella & $6.19^{a}$ & $5.68^{b}$ & $5.33^{c}$ & $5.18^{c}$ & 0.07 \\
\hline & Lactobacilli & $7.66^{\mathrm{a}}$ & $7.71^{\mathrm{a}}$ & $7.95^{\mathrm{b}}$ & $8.31^{\mathrm{c}}$ & 0.05 \\
\hline \multirow{3}{*}{ Cecum } & Escherichia coli & $7.91^{\mathrm{a}}$ & $7.79^{a}$ & $7.15^{b}$ & $6.91^{\mathrm{b}}$ & 0.86 \\
\hline & Salmonella & $6.71^{\mathrm{a}}$ & $6.54^{\mathrm{ab}}$ & $6.37^{\mathrm{b}}$ & $5.95^{c}$ & 0.60 \\
\hline & Lactobacilli & $8.32^{\mathrm{a}}$ & $8.13^{\mathrm{a}}$ & $8.61^{\mathrm{ab}}$ & $9.23^{c}$ & 0.89 \\
\hline
\end{tabular}

a,b,c Different letters in the same row indicate significant differences $(p<0.05)$.

${ }^{1}$ values represent the means \pm SEM of 10 Muscovy ducks per group. 
Table 5 - Effect of Bacillus subtilis natto on duodenum morphology of Muscovy ducks ${ }^{1}$

\begin{tabular}{lccccc}
\hline \multirow{2}{*}{ Items } & \multicolumn{4}{c}{ Levels of Bacillus subtilis natto, \% } & SEM \\
\cline { 2 - 5 } & $\begin{array}{c}0 \\
\text { (control) }\end{array}$ & 0.1 & 0.2 & 0.4 & \\
\hline $\begin{array}{l}\text { Villus width } \\
(\mu \mathrm{m})\end{array}$ & $132^{\mathrm{a}}$ & $138^{\mathrm{b}}$ & $140^{\mathrm{b}}$ & $146^{\mathrm{c}}$ & 0.89 \\
\hline $\begin{array}{l}\text { Villus height } \\
(\mu \mathrm{m})\end{array}$ & $1323^{\mathrm{a}}$ & $1345^{\mathrm{b}}$ & $1425^{\mathrm{c}}$ & $1478^{\mathrm{d}}$ & 10.09 \\
\hline $\begin{array}{l}\text { Crypt depth } \\
(\mu \mathrm{m})\end{array}$ & $250^{\mathrm{a}}$ & $247^{\mathrm{ab}}$ & $242^{\mathrm{c}}$ & $230^{\mathrm{d}}$ & 1.58 \\
\hline $\begin{array}{l}\text { Muscular } \\
\text { layer } \\
\text { thickness } \\
(\mu \mathrm{m})\end{array}$ & $214^{\mathrm{a}}$ & $218^{\mathrm{ab}}$ & $232^{\mathrm{c}}$ & $247^{\mathrm{d}}$ & 2.19 \\
\hline
\end{tabular}

$a_{a}, b, c, d$ Different letters in the same row indicate significant differences $(p<0.05)$.

${ }^{1}$ The height and width of 30 villi, the depth of 30 crypts and the thickness of 30 muscular layers were measured per replicate.

\section{Effect of Bacillus subtilis natto on immune functions in mucovy ducks}

Bacillus subtilis natto supplementation tended to improve the immune functions of Muscovy ducks. The results in Table 6 show that, compared with the control group, the indices of thymus, spleen and bursa of Fabricius improved when Bacillus subtilis natto was added to the diets, indicating Bacillus subtilis natto may improve the immune functions in Muscovy ducks. The addition of $0.1 \%$ did not influence the immune function ( $p>0.05$ ), while $0.2 \%$ and $0.4 \%$ dietary addition of Bacillus subtilis natto promoted significant results $(p<0.01)$.

Table 6 - Effect of Bacillus subtilis natto on immune organ indices in Muscovy ducks ${ }^{1}, \mathrm{~g} / \mathrm{kg}$

\begin{tabular}{|c|c|c|c|c|c|}
\hline \multirow{2}{*}{ Items } & \multicolumn{4}{|c|}{ Levels of Bacillus subtilis natto, \% } & \multirow{2}{*}{ SEM } \\
\hline & 0 (control) & 0.1 & 0.2 & 0.4 & \\
\hline Thymus & $2.18^{\mathrm{a}}$ & $2.20^{\mathrm{ab}}$ & 2.54 & $2.85^{d}$ & 0.05 \\
\hline Spleen & $0.73^{\mathrm{a}}$ & $0.79^{\mathrm{ab}}$ & $0.83^{b c}$ & $0.86^{c}$ & 0.01 \\
\hline $\begin{array}{l}\text { Bursa of } \\
\text { Fabricius }\end{array}$ & $1.26^{\mathrm{a}}$ & $1.29^{\mathrm{ab}}$ & $1.37^{c}$ & $1.42^{\mathrm{d}}$ & 0.02 \\
\hline
\end{tabular}

\footnotetext{
$a, b, c, d$ Different letters in the same row indicate significant differences $(p<0.05)$.
}

' values represent the means \pm SEM of 10 Muscovy ducks per group.

\section{DISCUSSION}

Previous studies showed that probiotics used as feed additives to replace antibiotics tended to improve the animal growth and health (Steiner et al., 2006). Zhang et al. (2005) reported that diets supplemented with $0.3 \%$ yeast (S. cerevisiae) cell components improved weight gain, feed intake, and feed conversion ratio of Ross broilers. Diets supplemented with $0.1 \% B$. subtilis powder increased the weight gain of 10-d-old male Arbor Acres broiler chicks maintained in a high temperature and humidity environment (Jin etal., 1996). Santoso et al. $(1995,2001)$ also demonstrated that diets supplemented with $0.5 \%$ B. subtilis fermentation product improved broiler growth performance. Diets supplemented with Bacillus licheniformis and $B$. subtilis improved the feed conversion ratio of AvianxAvian broilers (Mutus et al., 2006).

The findings obtained with Bacillus subtilis natto suggest that it may improve the growth performance of animals and as well as profitability. For instance, milk supplemented with Bacillus subtilis natto fed directly to calves promoted better growth performance by improving the average daily gain and feed conversion ratio, allowed earlier weaning, and benefitted the immune function of calves (Sun et al., 2010). Bacillus subtilis isolated from natto improved shrimp growth performance by increasing feed digestibility (Liu et al., 2009). When dietary Bacillus subtilis natto was fed chickens for 28 days, birds tended to present better growth performance and intestinal histology, as well lower ammonia emmission. Bacillus subtilis has the potential to be a beneficial microorganism in chickens (Samanya et al., 2002). In this study, we found that low levels of Bacillus subtilis natto in the diets of Muscovy ducks did not influence growth performance compared with the control group; however, the supplementation of $0.2 \%$ and $0.4 \%$ Bacillus subtilis natto to the diets of Muscovy ducks improved their weight gain, feed intake, and feed conversion ratio.

Our findings further indicate that the dietary supplementation of Bacillus subtilis natto significantly increased total protein, GOT, GPT, $A K P, T_{3}$ and $T_{4}$ contents in serum of Muscovy ducks, while decreased urea nitrogen, glucose, triglyceride, total cholesterol levels. Malmolf (1988) reported that the serum urea nitrogen concentration was related with the status of protein metabolism and amino acid balance. The serum concentration of urea nitrogen decreases when amino acids are well balanced. Total serum protein concentration is a parameter that reflects the ability of the liver to synthesize protein. This study indicated that Bacillus subtilis natto tended to increase the concentration of serum urea nitrogen and total serum protein. This may be related to enhanced protein intake and balanced amino acid status when Bacillus subtilis natto is added to the diet of Muscovy ducks.

Serum GOT and GPT are critical parameters to measure liver function. This experiment showed that Bacillus subtilis natto increased the serum GOT and 
GPT concentration. Alkaline phosphatase (AKP) is an enzyme that can catalyzes many kinds of lecithoid compounds to release inorganic phosphorus, which is extensively present in animal tissues, exerting its important function in the formation of the skeleton and fat. Results showed that the activity of AKP was high in Bacillus subtilis natto treated groups, but its mode of action needs to be further studied.

The levels of $T_{3}$ and $T_{4}$ in the peripheral blood plays several physiological functions, such as facilitating the differentiation, growth and development of tissues, stimulating DNA transcription and mRNA formation, promoting the synthesis of protein and enzymes, increasing the utilization of carbohydrates, and enhancing the disintegration of starch and fat (Ooi et al., 2004). After feeding Bacillus subtilis natto for six weeks, the levels of $T_{3}$ and $T_{4}$ in the blood of Muscovy ducks were measured and the results indicated that Bacillus subtilis natto increased the concentrations of $T_{3}$ and $T_{4}$, thus promoting enhanced nutrient metabolism and absorption and performance of Muscovy ducks. The changes in duodenum structure observed in this study are also better for absorption in nutrients.

Bacillus subtilis natto changed the microflora population in the intestine. It enhanced the growth and viability of lactobacilli through production of catalase and subtilisin, demonstrating the potential usefulness of Bacillus subtilis natto as a probiotic (Hosoi et al., 2000). Subtilisin, produced by Bacillus subtilis was found to be effective against staphylococcal enterotoxins (Osawa and Matsumoto, 1997). The administration of intact spores of Bacillus subtilis natto did not affect fecal Enterobacteriaceae and Enterococcus spp., but affected fecal Bacteroidaceae and Lactobacillus spp.; however, these changes require monosaccharides or oligosaccharides (Hosoi et al., 1999). In our study, it was observed that Bacillus subtilis natto provided better intestinal environment by reducing Escherichia coli and Salmonella numbers and increasing lactobacilli population in ileum and cecum of Muscovy ducks.

Thymus, spleen and bursa of Fabricius are the main immune organs involved in humoral immunity and cell immunity of animals. Thymus is the site of $\mathrm{T}$ cell maturation, and the bursa of Fabricius is required for $B$ cell (part of the immune system) development in birds. The function of the spleen and its responses to antigens are much like those of lymph nodes (Cooper et al., 1966). The dietary addition of Bacillus subtilis natto increased the percentage of $T$ and $B$ lymphocytes in the spleen, suggesting that dietary Bacillus subtilis natto had an effect on cellular immune responses
(Inooka et al., 1986). Chickens fed Bacillus subtilis natto in the diet from hatching until 15 or 30 days of age showed an increase in the ability to produce hemagglutinating antibody titers (Inooka and Kimura, 1983). Our results showed that Bacillus subtilis natto increased thymus, spleen and bursa of Fabricius indices, indicating Bacillus subtilis natto could enhance immune functions of Muscovy ducks.

In conclusion, the results of this study showed that the supplementation of Bacillus subtilis natto to the diets of Muscovy ducks improves their growth performance by increasing the absorption of protein, promoting hormone secretion, suppressing harmful microflora, promoting better development of the duodenum structure and enhancing the immune functions of Muscovy ducks. In addition, the results suggest that Bacillus subtilis natto is a potential candidate to be used as a probiotic to improve the growth performance of Muscovy ducks.

\section{ACKNOWLEDGMENTS}

This work was supported by grants from The National Natural Science Foundation of China (Nos.30771611 and 31072137), The Guangzhou Science Technology Plan Projects (No.2008Z1-E011), and Guangdong Provincial Finance Bureau Projects (No.2009-400).

\section{REFERENCES}

Cao XH, Liao ZY, Wang CL, Cai P, Yang WY, Fand MF, Huang GW. Purification and antitumour activity of a lipopeptide biosurfactant produced by Bacillus natto TK-1. Biotechnol. Applied Biochemistry 2009;52:97-106.

Chen KL, Kho WL, You SH, Yeh RH, Tang SW, Hsieh CW. Effects of Bacillus subtilis var. natto and Saccharomyces cerevisiae mixed fermented feed on the enhanced growth performance of broilers. Poultry Science 2009;88:309-315

Cooper MD, Peterson RDA, South MA, Good RA. The functions of the thymus system and the bursa system in the chicken. Journal of Experimental Medicine 1966;123:75

Hosoi T, Ametani A, Kiuchi K, Kaminogawa S. Changes in fecal microflora induced by intubation of mice with Bacillus subtilis (natto) spores are dependent upon dietary components. Canadian Journal of Microbiology 1999;45:59-66.

Hosoi T, Ametani A, Kiuchi K, Kaminogawa S. Improved growth and viability of lactobacilli in the presence of Bacillus subtilis (natto), catalase, or subtilisin. Canadian Journal of Microbiology 2000;46:892-897.

Hu Y, Ge G, Yuan W, Zhu R, Zhang W, Du L, Xue J. Characterization of fermented black soybean natto inoculated with Bacillus natto during fermentation. Journal of the Science of Food and Agriculture 2010;90:1194-1202.

Inooka S, Kimura M. The effect of Bacillus natto in feed on the sheep red blood cell antibody response in chickens. Avian Diseases 1983;27:10861089 
Inooka S, Uehara S, Kimura M. The effect of Bacillus natto on the T and B lymphocytes from spleens of feeding chickens. Poultry Science 1986; 65(6):1217-1219

Jin LZ, YW Ho, Abdullah, Jalaludin S. Influence of dried Bacillus subtilis and lactobacilli cultures on intestinal microflora and performance in broilers. Asian-australas. Journal of Animal Science 1996;9:397-403.

Liu CH, Chiu CS, Ho PL, Wang SW. Improvement in the growth performance of white shrimp, Litopenaeus vannamei, by a protease-producing probiotic, Bacillus subtilis E20, from natto. Journal of Applied Microbiology 2009;107:1031-1041.

Malmolf K. Amino acid in farm animal nutrition metabolism, partition and consequences of imbalance. Journal of Agricultural Research 1988;18:191-193.

Mutus R, Kocabagli N, Alp M, Acar N, Eren M, Gezen SS. The effect of dietary probiotic supplementation on tibial bone characteristics and strength in broilers. Poultry Science 2006;85:1621-1625

Omura K, Hitosugi M, Zhu X, Ikeda M, Maeda H, Tokudome S. A newly derived protein from Bacillus subtilis natto with both antithrombotic and fibrinolytic effects. Journal of Pharmacological Sciences 2005;99: 247-251

Ooi GT, Tawadros N, Escalona RM. Pituitary cell lines and their endocrine applications. Molecular Celular Endocrinology 2004;228:1-21.

Osawa R, Matsumoto K. Digestion of staphylococcal enterotoxin by Bacillus natto. Antonie Van Leeuwenhoek 1997;71:307-311.

Samanya M, Yamauchi KE. Histological alterations of intestinal villi in chickens fed dried Bacillus subtilis var. natto. Comparative Biochemistry and Physiology. A. Molecular and Integrative and Physiology 2002;133:95-104

Santoso U, Tanaka K, Ohaniand S, Saksida M. Effect of fermented product from Bacillus subtilis on feed efficiency, lipid accumulation and ammonia production in broiler chicks. Asian-australas. Journal Animal Science 2001:14:333-337.
Santoso U, Tanaka K, Ohtania S. Effect of dried Bacillus subtilis culture on growth, body composition and hepatic lipogenic enzyme activity in female broiler chicks. British Journal of Nutrition 1995;74:523-529.

Shih IL, Yu YT, Shieh CJ, Hsieh CY. Selective production and characterization of levan by Bacillus subtilis (Natto) Takahashi. Journal Agricultural and Food Chemistry 2005; 53:8211-8215.

Steiner T. Managing gut health. Natural growth promoters as a key to animal performance. Nottingham (UK): University Press.

Sun P, Wang JQ, Zhang HT. Effects of Bacillus subtilis natto on performance and immune function of preweaning calves. Journal Dairy Science 2010;93: 5851-5855

Tannock GW. Molecular assessment of intestinal microflora. American Journal of Clinical Nutrition 2001;73:410-414

Wang CL, Ng TB, Yuan F, Liu ZK, Liu F. Induction of apoptosis in human leukemia K562 cells by cyclic lipopeptide from Bacillus subtilis natto T-2. Peptides 2007;28: 1344-1350.

Yamashita T, Oda E, Giddings JC, Yamamoto J. The effect of dietary bacillus natto productive protein on in vivo endogenous thrombolysis. Pathophysiology of Haemostasis and Thrombosis 2003;33:138-143.

Yanagisawa Y, Chatake T, Chiba-Kamoshida K, Naito S, Ohsugi T, Sum $\mathrm{H}$, Yasuda I, Morimoto $Y$ Purification, crystallization and preliminary $X$-ray diffraction experiment of nattokinase from Bacillus subtilis natto. Acta Crystallografica Section F Structural Biology Crystallization Communications 2010;66:1670-1673.

Zhang AW, BD Lee, SK Lee, KW Lee, GH An, KB Song and CH Lee. Effects of yeast (Saccharomyces cerevisiae) cell components on growth performance, meat quality and ileal mucosa development of broiler chicks. Poultry Science 2005;84: 1015-1021. 
